\title{
EDUCACIÓN
}

\section{Extensión universitaria: su aporte en la formación de los estudiantes del último curso de las Carreras de Grado de la Universidad Iberoamericana, Sede San Lorenzo, año 2018}

\author{
Rosa del Carmen Conti ${ }^{1}$
}

\section{Resumen}

Introducción: Se analiza el aporte del programa de extensión universitaria que requiere la inversión de tiempo de directivos, docentes y estudiantes, planificación, ejecución y evaluación, por lo que es importante conocer más detalladamente la realidad sobre su implementación y su aporte en la formación de los estudiantes universitarios.

Objetivo: Analizar el aporte del programa de extensión universitaria en la formación de los estudiantes, de los últimos cursos de las carreras de grado de la Universidad Iberoamericana, sede San Lorenzo, año 2018.

Material y Método: Investigación de diseño no experimental, de tipo descriptivo y de enfoque mixto, cuali/cuantitativo. Sujetos de investigación: un directivo, nueve docentes de las diferentes carreras y ochenta y cinco estudiantes del 4 음 curso séptimo semestre y 5 o curso noveno semestre de las nueve carreras de la Universidad Iberoamericana, sede San Lorenzo. Las técnicas de recopilación de datos fueron encuesta, entrevista individual y grupo focal.

Resultados: La investigación, resalta un interés de los estudiantes hacia el trabajo de campo, de la extensión universitaria, ubicando las actividades según sus intereses formativos. Desarrollan actividades que van más allá de la propia naturaleza académica, generar y transmitir conocimientos, contribuir al desarrollo social y sobre todo como una función orientadora de la universidad. Los docentes tienen conocimientos de la importancia de llevar a la práctica lo teórico, en los diferentes espacios que propone la universidad enfatizando los aprendizajes adquiridos, como también adquisición de habilidades, competencias y actitud de compromiso con la sociedad. Promover más la extensión para apoyar e incidir de manera más significativa en las políticas públicas. Planificar proyectos que involucren a todos los estudiantes en ambos semestres. En cuanto a la gestión de la extensión universitaria, no existe una instancia específica en la estructura de la universidad, sino, de acuerdo a lo que

1. UNIBE. Facultad de Humanidades. Psicopedagogía.

Tesis de Maestría para optar por el título de Magister en Educación con énfasis en Gestión educativa de calidad en la Universidad Iberoamericana. La investigación fue realizada en al año 2018.

E-mail: elenaconti.cic@gmail.com

DOI: 10.26885/rcei.foro.2018.78 


\section{Extensión universitaria. Conti}

va surgiendo y dependiendo de, en qué nivel surgen las iniciativas, se identifican los responsables. En el proceso de implementación los protagonistas principales son los directivos, catedráticos y estudiantes. Se cuenta con un registro de actividades para el estudiante. Se prevén recursos, se realiza un seguimiento de las actividades, como también una evaluación asistemática de las mismas.

Conclusiones: En relación a las actividades de extensión universitaria, la de mayor significatividad constituyen las demostraciones prácticas, indicando que la teoría es importante, pero mucho más la práctica en lo que realizan como actividad. Existen propósitos claros de extensión universitaria, como ser devolver a la comunidad lo que están recibiendo, en forma de conocimientos, servicios; vincular a los estudiantes con la sociedad a fin de formar el sentido de responsabilidad y fortalecer la relación universidad-comunidad. El aporte que realiza el programa de extensión universitaria en la formación de los estudiantes, es significativo, promueve la iniciativa, la creatividad, unir la teoría con la práctica. Las actividades tienen una débil vinculación con la carrera, pero favorecen la conexión entre la teoría y la práctica, además del desarrollo de habilidades sociales, personales. Los estudiantes consideran significativos los espacios de ejecución para las actividades, como el aporte a la formación personal. Como también un alto número de carreras, que consideran que el aporte es poco. Existe una buena gestión dentro de la universidad que tiende a ser participativa, ya que en la planificación y la ejecución de las actividades de extensión universitaria participan, en la mayoría de los casos, diversos actores educativos. Existe un seguimiento de las actividades, pero aún no se encuentra sistematizada la evaluación del impacto de las mismas.

Palabras clave: extensión universitaria, gestión, formación.

\section{RefERENCIAS}

Ávila, O. S. (2008) - Estudios de extensión en humanidades: Hacer y pensar con otros en la universidad pública. Revista de Estudios de Extensión en Humanidades, 1(1).

Ballesteros, M. V. (2010): La extensión universitaria como proceso de Comunicación. Revista Electrónica sobre Extensión Universitaria. Recuperado de http://perio.unlp.edu.ar/ojs/index.php/ extensionenred/article/viewFile/158/489

Cano, A. \& Castro, D. (2012). Análisis de los modelos pedagógicos en las prácticas educativas universitarias que integran la extensión a la formación curricular, Informe de investigación. Administración Nacional de Educación Pública de Uruguay.

Menendez, G. (2001). La Extensión Universitaria. Recuperado de https://www. blogeduca.com/5-características-de-las-universidades-del-futuro/

Tunnermann, C. (2000). El nuevo concepto de la Extensión Universitaria. 